\title{
UV-Licht bringt Sonnenschäden der Haut an den Tag
}

\begin{abstract}
Durch Abfotografieren von Gesichtern im UV-Licht treten bei Kindern mit entsprechendem Hauttyp ausgeprägte Sonnenschäden hervor, die ein erhöhtes Risiko für eine Melanomentwicklung darstellen.
\end{abstract}

- Unter den Malignomen weisen die Melanome die höchsten Zuwachsraten auf. Bei Frauen zwischen 25 und 29 Jahren ist das maligne Melanom gegenwärtig eine der häufigsten malignen Erkrankung. Die wichtigsten Risikofaktoren sind zum einen die Sonnenexposition, zum anderen aber auch persönliche phänotypische Risiken wie Hauttyp, Haar- und Augenfarbe, Vorhandensein von Sommersprossen und multiplen Naevi pigmentosi. Empfohlene Basismaßnahmen wie Vermeiden der Mittagssonne, Bedeckung der Haut mit Kleidung, Tragen von Hüten, Anwendung von Sonnencremes und Meidung von Bräunungsstudios werden nur von einer Minderheit gerade der jungen Leute befolgt. Mithilfe der UV-Fotografie gelingt es, Sonnenschäden der Haut, die mit dem bloßen Auge noch kaum erkennbar sind, deutlich sichtbar zu machen.

Das Gesicht von 620 Kindern im Alter von elf und zwölf Jahren wurde im UV-Licht fotografiert und die Aufnahmen mithilfe eines Computerprogramms systematisch ausgewertet. Verfälschende Einflüsse wie Cremes, Makeup oder Schmuck waren nicht erlaubt. Gleichzeitig nahm ein Team bestehend aus einem Dermatologen, einem Pädiater, einem Medizinstudenten und sieben Kinderkrankenschwestern sorgfältige Hautuntersuchungen vor, bei der die Zahl der Pigmentnävi am ganzen Körper gezählt wurde, wobei allerdings Genitale, Gesäß, behaarte Kopfhaut und Brüste bei Mädchen ausgenommen wurden.

Die Unterscheidung zwischen Pigmentnävi, Sommersprossen und Caféau-lait-Flecken erfolgte blickdiagnostisch. Fast $80 \%$ der Kinder gehörten der weißen Rasse an, 13,5\% stammten aus
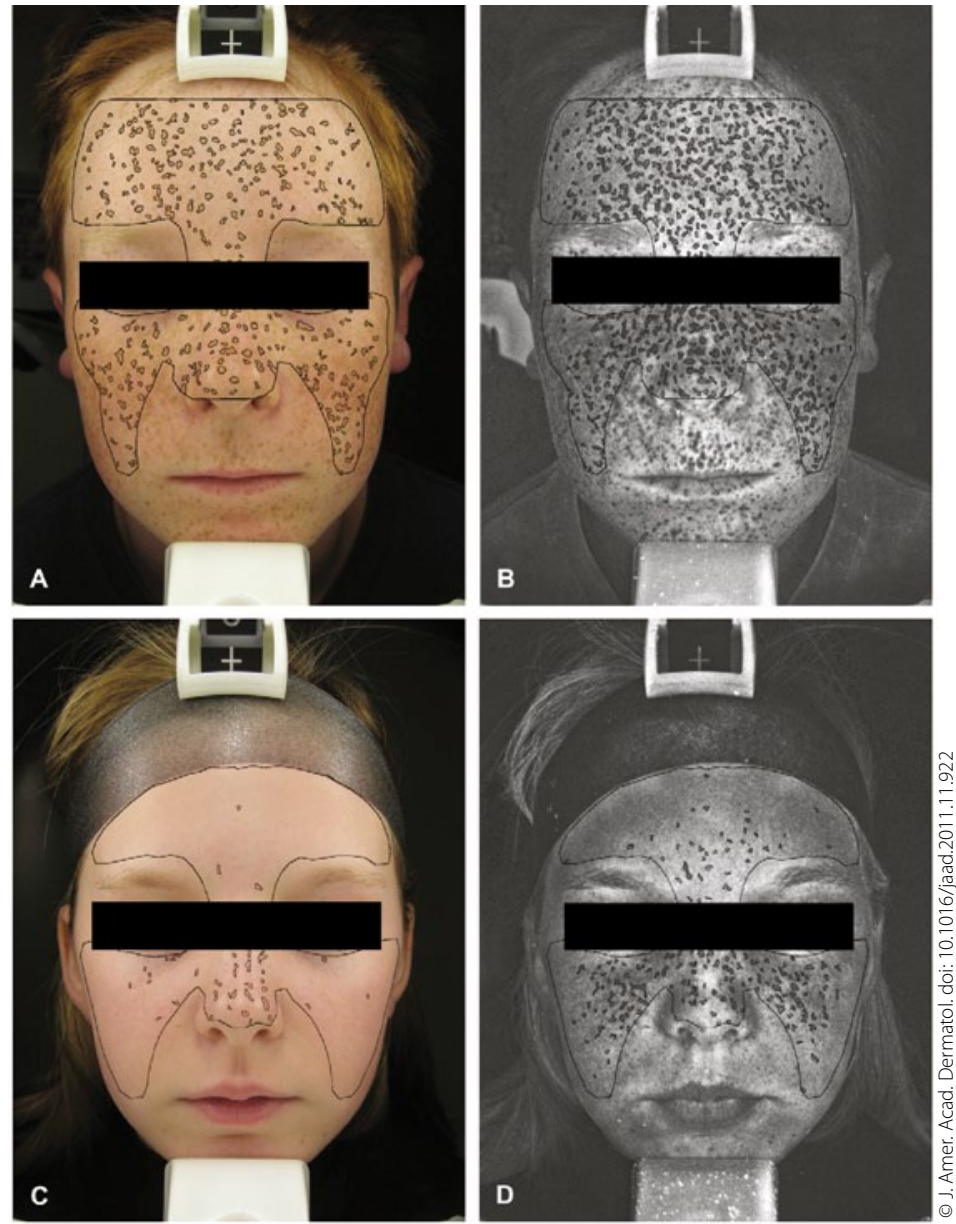

Fotografien mit sichtbarem (links) und UV-Licht (rechts);

A und B: Mädchen mit rotem Haar; C und D: Mädchen mit hellbraunem Haar; hyperpigmentierte Hautareale sind jeweils durch Linien gekennzeichnet.

Mexiko, $3 \%$ waren schwarz und $4 \%$ asiatisch. Die im UV Licht erkennbaren Sonnenschäden korrelierten deutlich mit den phänotypischen Risikofaktoren für Melanome. Sie waren am größten bei Kindern weißer Hautfarbe mit sehr heller Haut, roten Haaren, blauen Augen sowie vielen Sommersprossen und Pigmentnävi. Von allen genannten Eigenschaften wiesen die Sommersprossen den stärksten prädiktiven Wert für Sonnenschäden auf.

\section{Kommentar}

Im Internet wird ein Programm verbreitet, mit dem man sein eigenes aktuelles Portraitfoto so verändern kann, wie man in 20
Jahren aussehen wird, wenn man raucht und wenn man nicht raucht. Angeblich gelingen mit diesem Programm gerade bei jungen Mädchen die größten Erfolge beim Erreichen einer Nikotinabstinenz. Vielleicht kann die Darstellung der Sonnenschäden im UV-Licht auch die Heliophilie der Kinder verringern und gleichzeitig das Verantwortungsbewusstsein der Eltern erhöhen. (siehe auch Beitrag S. 43)

H. S. FÜESSL =

- R. G. Gamble et al.

(Korres.: robert.dellavalle@ucdenver.edu.): Sun damage in ultraviolet photographs correlates with phenotypic melanoma risk factors in 12-year-old children. J. Amer. Acad. Dermatol. doi: 10.1016/jaad.2011.11.922 